•数据论文・

\title{
中国野生杜鹃花属植物名录与地理分布数据集
}

程洁婕®，李美君，袁桃花，黄红，杨桂丽，白新祥*

贵州大学林学院, 贵阳 550025

摘要：杜鹃花属(Rhododendron)植物分布广泛，生存环境多样，类群结构复杂，深入分析其地理分布格局与特征，可为种质资 源保育和利用等提供依据。本文基于大量基础数据及文献资料, 更新了中国陆域分布的野生杜鹃花属植物物种名录, 统计了 其物种多样性、组成成分等信息, 建立了中国野生杜鹃花属植物地理分布数据库, 旨在为种质资源调查及引种应用研究提供 参考。截至2021年7月, 共记载7亚属720种(包括114变种、45亚种和2变型), 其中中国特有种450种。除宁夏和新疆干旱荒漠 地带外，中国其他各省区均有野生杜鹃花属分布，其中云南省分布393种，是省级尺度物种丰富度及特有性最高的区域; 其次 为四川省(278种)及西藏自治区(271种)。县级尺度贡山独龙族怒族自治县与察隅县以 134 种并列物种丰富度第一, 其次是德钦 县128种。

关键词: 杜鹃花属; 物种多样性; 特有种; 地理分布

数据库(集)基本信息简介

\begin{tabular}{ll} 
数据库(集)名称 & 中国野生杜鹃花属植物名录与地理分布数据集 \\
作者 & 程洁婕, 李美君, 袁桃花, 黄红, 杨桂丽, 白新祥 \\
通讯作者 & 白新祥(254715174@qq.com) \\
时间范围 & 截至2021年7月 \\
地理区域 & 中国 \\
分布范围精确程度 & 县级行政区 \\
文件大小 & 1.65 MB \\
数据格式 & *.doc \\
数据链接 & http://dataopen.info/home/datafile/index/id/218 \\
& http://doi.org/10.24899/do.202109001 \\
& https://www.biodiversity-science.net/fileup/1005-0094/DATA/2021152.zip \\
数据库(集)组成 & 数据集共2个数据文件, 其中包括: (1)中国野生杜鹃花属植物物种名录(亚属、种组成情况)及地理分布信息(物种地理分 \\
& 布如省级、县级行政区; 物种分布海拔); (2)中国野生杜鹃花属植物名录及地理分布信息数据库的主要参考书籍目录(出 \\
& 版专著与保护区科考集书目名称、作者、出版年份、出版社) \\
\hline
\end{tabular}

程洁婕, 李美君, 袁桃花, 黄红, 杨桂丽, 白新祥 (2021) 中国野生杜鹃花属植物名录与地理分布数据集. 生物多样性, 29, 1175-1180. doi: 10.17520/biods.2021152.

Cheng JJ, Li MJ, Yuan TH, Huang H, Yang GL, Bai XX (2021) A dataset on wild Rhododendron and geographical distribution information in China. Biodiversity Science, 29, 1175-1180. doi: 10.17520/biods.2021152.

\section{A dataset on wild Rhododendron and geographical distribution information in China}

Jiejie Cheng ${ }^{(i D}$, Meijun Li, Taohua Yuan, Hong Huang, Guili Yang, Xinxiang Bai*

College of Forestry, Guizhou University, Guizhou 550025

\section{ABSTRACT}

The genus Rhododendron is widely distributed, lives in diverse habitats, and its group structure is complex. An in-depth analysis of its geographical distribution pattern and characteristics can provide a basis for conservation and utilization

收稿日期: 2021-04-22; 接受日期: 2021-09-03

基金项目: 国家自然科学基金(31960328)和贵州省野生观赏植物资源调查(701256192201)

* 通讯作者 Author for correspondence. E-mail: 254715174@qq.com 
of germplasm. Based on current literature and data, this paper updates the list of species of wild Rhododendron distributed in China, explores species composition, and establishes a geographical distribution database of wild Rhododendron in China. As of July 2021, 720 species (including 114 varieties, 45 subspecies and 2 forms) of 7 subgenera have been recorded, of which 450 are endemic to China. The genus Rhododendron is distributed in all provinces of China except the arid desert areas of Ningxia and Xinjiang. Over half of all Rhododendron (393) species are distributed in the Yunnan Province, which is the highest species richness and endemism at the provincial level. There are 278 species in Sichuan province and 271 species in Tibet Autonomous Region. At the county level, Gongshan and Zayul counties are tied for having the most species of Rhododendron at 134 species, followed by 128 species in Deqin County. This study revised and updated the list of wild Rhododendron plants and their geographical distribution in China in order to provide reference for germplasm investigation and application research.

Key words: Rhododendron; species diversity; endemic species; geographic distribution

\section{Database/Dataset Profile}

\begin{tabular}{|c|c|}
\hline Title & A dataset on wild Rhododendron and geographical distribution information in China \\
\hline Authors & Jiejie Cheng, Meijun Li, Taohua Yuan, Hong Huang, Guili Yang, Xinxiang Bai \\
\hline Corresponding author & Xinxiang Bai (254715174@qq.com) \\
\hline Time range & Until July 2021 \\
\hline Geographical scope & China \\
\hline Accuracy of distribution range & County districts \\
\hline File size & $1.65 \mathrm{MB}$ \\
\hline Data format & *.doc \\
\hline Data link & $\begin{array}{l}\text { http://dataopen.info/home/datafile/index/id/218 } \\
\text { http://doi.org/10.24899/do.202109001 } \\
\text { https://www.biodiversity-science.net/fileup/1005-0094/DATA/2021152.zip }\end{array}$ \\
\hline Database/Dataset composition & $\begin{array}{l}\text { The dataset consists of two data files: (1) Dataset on wild Rhododendron species in China (subgenera, species } \\
\text { composition) and geographical distribution of wild Rhododendron species in China (location of species distribution, } \\
\text { e.g. provincial and county-level administrative regions; altitude of species distribution). (2) List of wild } \\
\text { Rhododendron species in China and geographical distribution information database main reference books catalogue } \\
\text { (title, author, year of publication, publisher of bibliography of published monographs and collections of protected } \\
\text { areas). }\end{array}$ \\
\hline
\end{tabular}

杜鹃花属(Rhododendron)隶属于杜鹃花科，全 世界约有1,200余种(刘德团等, 2020), 广泛分布于 亚洲、北美洲和欧洲。杜鹃花属植物大多株形优美、 花大色艳, 具有极高的观赏价值, 素有 “木本花卉 之王”的美誉, 在世界园艺界占有重要地位, 对斜 坡地形的稳定与河流流域保护等方面也有着重要 的作用(Yu et al, 2017)。该属植物种类繁多、分布广 泛, 但大部分缺乏充分的资源调查, 其分布区域和 生境等基础资料不详, 保育工作难以开展。在生境 丧失、全球气候变化、人类活动等因素共同作用下, 杜鹃花属植物资源破坏严重(覃海宁等, 2017)。因此 加强该属植物物种多样性及地理分布等基础研究 十分必要。

中国是野生杜鹃花属植物资源最丰富的国家, 是世界杜鹃花属的现代分布中心和分化中心之一, 其分布区约占我国陆域面积的 60\%-65\% (庄平, 2012)。相关地理分布研究多侧重于对某一类群或物 种, 针对不同尺度、地域进行资源调查及区系组成
的研究(耿玉英, 2010); 或以自然地理区划为单元， 探讨杜鹃花属植物分布型的划分及其分布格局的 成因, 以及对重要的分布区域如青藏高原、横断山 区及秦岭山区的资源情况展开研究(庄平等, 2013)。 自《中国植物志》、Flora of China等专著出版以来, 有大量新类群不断被报道(Du et al, 2020), 使得我 国杜鹃花属植物早已超过文献记载的570余种, 然 而各级行政区的具体分布物种模糊不清、数量不明, 有待进一步梳理。本文通过确立物种名录, 系统地 开展针对中国野生杜鹃花属植物的相关文献检索, 对物种组成、特有性、水平地理分布及垂直分布海 拔等方面进行数据挖掘, 以完善中国野生杜鹃花属 植物名录及其地理分布信息, 拟为进一步深入开展 中国野生杜鹃花属植物研究奠定基础。

\section{数据采集和处理方法}

\section{1 数据来源}

物种名录与地理分布数据集的主要数据来源 
为: (1)植物志书, 如 《中国植物志》(第14卷)、Flora of China (第18卷) 以及地方植物志书、植物名录及编 目; (2)相关书籍, 如 《青藏高原维管植物及其生态 地理分布》《云南杜鹃花》《中国广西杜鹃花》 《中 国杜鹃花属植物》《滇黔桂喀斯特地区种子植物名 录》等; (3)期刊论文, 以截至2021年7月发表在学术 期刊中的有关野生杜鹃花属植物新类群和新记录 的文献为补充材料, 并包括已公开发表的博硕士学 位论文(刘仁林, 2007; 张玉节, 2007 ${ }^{\circledR}$; 王颖, $2008^{(2)}$ ); (4) 标本数据, 如中国数字植物标本馆 $(\mathrm{CVH}$, https://www.cvh.ac.cn)标本数字化数据与杜鹃花属 分类专家的鉴定资料; (5)以中国各级自然保护区科 学考察集等记载的杜鹃花属物种为本底资料。

本研究所采用的分类系统沿用《中国杜鹃花属 植物》(耿玉英, 2014), 接受关于有鳞类群的修订和 将马银花亚属的4组提升为 4 亚属的修订, 故中国杜 鹃花属分为 7 亚属, 即杜鹃花亚属 (Subgen. Rhododendron)、常绿杜鹃花亚属 (Subgen. Hymenanthe)、羊蹶躅亚属(Subgen. Pentanthera)、 映山红亚属(Subgen. Tsutsusi)、马银花亚属(Subgen. Azaleastrum)、长荵杜鹃花亚属(Subgen. Choniastrum) 和叶状苞亚属(Subgen. Therorhodion)。通过查阅各 类植物志、专著和期刊文献, 初步确定野生杜鹃花 属植物名录, 然后邀请相关植物分类专家审核, 根 据专家的意见与建议对名录初稿进行必要的修订、 补充和完善, 最终确定中国野生杜鹃花属植物物种 名录。

\section{2 数据处理方法}

物种名录建立工作主要包括: (1)使用WPS软件 对收集的物种亚属名、组名、亚组名、种名(包括拉 丁学名)、分布海拔及分布地点等数据信息进行整 理。(2)参考2021年5月发布的《中国生物物种名录》 (2021版) (The Biodiversity Committee of Chinese Academy of Sciences, 2021)中对部分物种的处理, 删除重复学名以及作并种处理的物种, 更新物种接 受状态, 完善名录。

地理分布数据集建立主要工作流程: (1)分布信 息的获取及梳理。从文献资料及标本采集记录中提

(1) 张玉节 (2007) 甘肃省杜鹃花科植物系统分类与区系地理. 硕 士士学位论文, 甘肃农业大学, 兰州.

(2) 王颖 (2008) 四川野生杜鹃花属植物资源的调查与评价. 硕士 士学位论文, 北京林业大学, 北京.
取杜鹃花属植物的相关分布信息, 即采集记录中填 写的研究区域(如自然保护区、自然公园等及其所在 省级(含直辖市、自治区)、县级行政区。在标本查 阅过程中, 对采集信息进行必要的核对, 如有标本 物种鉴定存疑及地理分布信息记录错误等情况, 则 删除该条分布记录。(2)地理信息的校正。在查阅资 料的基础上收集并整理各类数据, 构建中国野生杜 鹃花属植物地理分布数据集。进一步汇总上述资料 所包含的分布信息, 将相关信息录入数据集。(3)数 据的精确性校正。(i)删除重复记录数据; (ii)删除采 自引种栽培区域的标本数据; (iii)对地名逐一进行校 对, 并根据中国民政部2021年5月新发布的最新县 级行政区划、中国数字植物标本馆新旧地名转换以 及国家标本资源共享平台(NSII, http://www.nsii.org. $\mathrm{cn} /$ ) 区划变迁查询工具等方式进行新旧地名转换。

地理分布数据集文件中主要包含编码、属名、 亚属名、组名、亚组名、种名(包括拉丁学名)、特 有性、分布地点(省级、县级)以及分布海拔等信息。 统一将所有物种地理分布精度转换为两级, 分别为 省级及县级行政单元。

\section{数据描述}

\section{1 中国野生杜鹃花属植物物种多样性}

中国野生杜鹃花属植物共计7亚属720种(其中 包括 114 个变种、 45 个亚种和 2 个变型)。其中常绿杜 鹃花亚属是包含物种数最多的亚属, 共372种, 占 物种总数的 $51.7 \%$; 杜鹃花亚属共计 251 种, 占物种 总数的 $34.9 \%$, 这两个亚属是中国野生杜鹃花属植 物的主要组成部分。含5-100种的属有映山红亚属、 马银花亚属、长荵杜鹃花亚属, 合计 96 种, 占物种 总数的 $13.3 \%$ 。中国野生杜鹃花属植物在各亚属中 数量差异较大, 多则上百种, 少则仅有 1 种, 充分说 明较高等级的分类群在种级水平分化差异很大。

\section{2 中国野生杜鹃花属植物物种特有性}

中国野生杜鹃花属植物特有成分丰富, 中国特 有种共 450 种, 占总种数的 $62.5 \%$ 。将特有种数占该 属总物种数的比例定义为特有率, 以此来分析亚属 的特有性, 得出中国特有率及省级特有率, 各项参 数如表1。中国特有率在亚属中分布较为均匀, 大部 分亚属的特有率在 0.5 以上, 仅叶状苞亚属特有率 为 0 。而特有率较高的多型亚属的存在则可能反映 
出中国是这些亚属的分化中心。

\section{3 数据质量控制和评估}

物种名录与地理分布数据集的数据来源: (1)相 关植物志书、植物名录及编目共计 90 本; (2)杜鹃花 属相关专著共计9本; (3)截至2021年7月发表的野生 杜鹃花属植物新类群和新记录的相关文献共计 180 篇(其中英文48篇), 已公开发表的有关博、硕士学位 论文18篇; (4)中国各级自然保护区科学考察集等相 关记载资料共计 95本; (5)中国数字植物标本馆标本 数字化数据与杜鹃花属分类专家的分类鉴定资料, 主要来源于中国科学院植物研究所标本馆 $(\mathrm{PE})$ 、中
国科学院昆明植物研究所标本馆(KUN)、中国科学 院华南植物园标本馆(IBSC)、广西植物研究所标本 馆(IBK)、中国科学院成都生物研究所植物标本馆 $(\mathrm{CDBI}) 、$ 中国科学院西北高原生物研究所植物标本 馆(HNWP)、华西亚高山植物园标本室(WCSBG)、 江西省中国科学院庐山植物园标本馆(LBG)等15个 国内植物标本馆。共计查阅标本 96,422 份，除去暂 无照片的部分共计59,342份。数据集收集的信息中, 省级分布信息数据 1,874 条; 县级分布信息数据 8,319 条; 海拔范围信息数据712条。各省级行政区 相关标本数量如图1所示。分析标本采集时间发现， 3 个标本采集峰值分别为1957、1980和2004年。今

表1 中国杜鹃花属植物亚属的种数和特有种数

Table 1 Number of species and endemic species in subgenus of Rhododendron from China

\begin{tabular}{|c|c|c|c|c|c|c|}
\hline 亚属 & 种数 & 占中国总种数的比例 & 中国特有种 & 占中国特有种总数的比例 & | 变种 & 亚种 \\
\hline Subgenus & Species & $\begin{array}{l}\text { Ratio of species in } \\
\text { China (\%) }\end{array}$ & $\begin{array}{l}\text { No. of Chinese endemic } \\
\text { species (CES) }\end{array}$ & Ratio of CES in China (\%) & Variety & Subspecies \\
\hline 常绿杜鹃花亚属 Subgen. Hymenanthe & 372 & 51.7 & 251 & 55.8 & 67 & 31 \\
\hline 杜鹃花亚属 Subgen. Rhododendron & 251 & 34.9 & 130 & 28.9 & 31 & 13 \\
\hline 映山红亚属 Subgen. Tsutsusi & 61 & 8.5 & 44 & 9.8 & 9 & 3 \\
\hline 马银花亚属 Subgen. Azaleastrum & 9 & 1.3 & 6 & 1.3 & 1 & 0 \\
\hline 长芯杜鹃花亚属 Subgen. Choniastrum & 24 & 3.3 & 16 & 3.6 & 6 & 0 \\
\hline 羊蹶躅亚属 Subgen. Pentanthera & 2 & 0.3 & 1 & 0.2 & 0 & 0 \\
\hline 叶状苍亚属 Subgen. Therorhodion & 1 & 0.1 & 0 & 0.0 & 0 & 0 \\
\hline
\end{tabular}

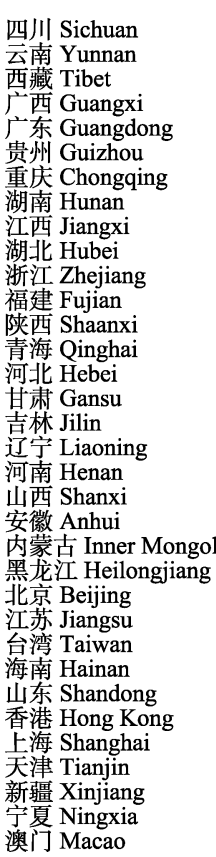

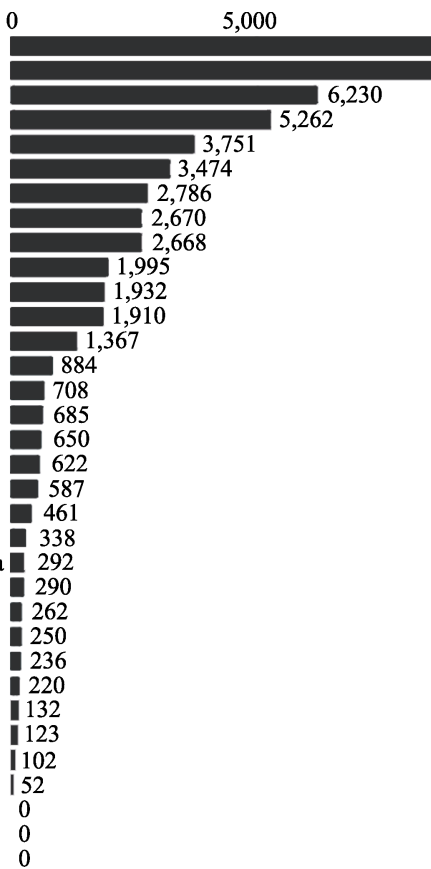

10,000

15,000

20,000

25,000

图1 中国野生杜鹃花属省级行政区标本数量

Fig. 1 The number of wild Rhododendron specimens from provincial regions of China 
后可整理相应标本记录空白区、标本空白种、彩色 照片空白种名录, 这对植物资源的数字化数据库 (标本、彩色照片、文献)的建设具有一定的科学意 义(张玉雪等, 2018)。

\section{4 数据使用方法和建议}

随着相关文献资料与标本的不断数字化, 越来 越多的数据可供科研人员使用, 这为分析物种分布 状况及保育工作提供了便利。汇总分散的多来源子 集信息, 建立物种分布数据集, 可用作描述物种的 完整空间覆盖范围, 选择优先保护区域以及预测物 种丰富度和潜在分布位置模型的主要决策工具。多 来源的数据极具价值, 但同时可能存在诸多因素导 致的误差, 包括分类鉴定错误, 数据记录错误, 野 外调查路线、地点、方式的偏好等因素均会对数据 精确度产生影响。人类活动干扰对杜鹃花属植物资 源的数量、生境均造成了一定的影响, 导致获取的 地理分布数据或因年代久远等原因与实际情况不 尽相同, 这些都是野生植物资源研究存在的问题 (Yu et al, 2019)。另外, 本底资源普查与数字标本库 建立工作需要引起相关研究人员更多的重视。今后 可开展针对数据缺乏及濒危类群系统的资源调查, 根据最新的数据重新进行评估; 摸清资源本底现状, 采集和保存种质资源和DNA材料; 可优先开展横 断山区、青藏高原等杜鹃花多样性中心和分布中心 的资源调查工作。系统地探索和研究种质资源分布 情况, 对确定优先保护区域并开展有效监测及其保 育具有重要意义(Yu et al, 2015)。

致谢: 感谢审稿过程中专家对此数据论文结构及内 容提出的宝贵建议!

\section{作者分工}

程洁婕负责植物标本查阅及记录、物种分类情况核查、 地理分布信息及海拔分布数据统计; 李美君负责相关资料 收集汇总; 袁桃花负责部分植物标本查阅及记录; 黄红负责 部分地理分布信息数据统计及地理分布数据校对; 杨桂丽 负责部分海拔分布数据统计; 白新祥负责提供数据资源及 物种分类情况核查。

\section{ORCID}

程洁婕 (D) https://orcid.org/0000-0002-6787-6790

\section{参考文献}

Du C, Liao S, Boufford DE, Ma JS (2020) Twenty years of Chinese vascular plant novelties, 2000 through 2019. Plant Diversity, 42, 393-398.

Geng YY (2010) Ammendments to original papers of some species of Rhododendron by Flora Reipublicae Popularis Sinicae cited. Guihaia, 30, 4581 . (in Chinese with English abstract) [耿玉英 (2010) 关于《中国植物志》杜 鹃花属部分名称原始文献引用的讨论. 广西植物, 30, 458-461.]

Geng YY (2014) The Genus Rhododendron of China. Shanghai Scientific \& Technical Publishers. (in Chinese) [耿玉英 (2014) 中国杜鹃花属植物. 上海科学技术出版社, 上海.]

Liu DT, Chang YH, Ma YP (2020) Unclear resource background seriously restricts biodiversity conservation of Rhododendron in China. Plant Science Journal, 38, 517-524. (in Chinese with English abstract) [刘德团, 常宇 航, 马永鹏 (2020) 本底资源不清严重制约我国杜鹃花 属植物的生物多样性保护. 植物科学学报, 38, 517-524.]

Liu RL (2007) Study on Systematic Classification of Subgenus Tsutsui (sweet) Pojarkova of Rhododendron in China. PhD dissertation, Jiangxi Agricultural University, Nanchang. (in Chinese with English abstract) [刘仁林 (2007) 中国杜鹃 属映山红亚属植物系统分类研究. 博士学位论文, 江西 农业大学, 南昌.]

Qin HN, Yang Y, Dong SY, He Q, Jia Y, Zhao LN, Yu SX, Liu HY, Liu B, Yan YH, Xiang JY, Xia NH, Peng H, Li ZY, Zhang ZX, He XJ, Yin LK, Lin YL, Liu QR, Hou YT, Liu Y, Liu QX, Cao W, Li JQ, Chen SL, Jin XH, Gao TG, Chen WL, Ma HY, Geng YY, Jin XF, Chang CY, Jiang H, Cai L, Zang CX, Wu JY, Ye JF, Lai YJ, Liu B, Lin QW, Xue NX (2017) Threatened Species List of China's Higher Plants. Biodiversity Science, 25, 696744. (in Chinese and in English) [覃海宁, 杨永, 董仕勇, 何强, 贾渝, 赵莉娜, 于胜祥, 刘慧圆, 刘博, 严岳鸿, 向建英, 夏念和, 彭华, 李振宇, 张志翔, 何兴金, 尹林克, 林余霖, 刘全儒, 侯 元同, 刘演, 刘启新, 曹伟, 李建强, 陈世龙, 金效华, 高 天刚, 陈文俐, 马海英, 耿玉英, 金孝锋, 常朝阳, 蒋宏, 蔡蕾, 蔵春金金, 武建勇, 叶建飞, 赖阳均, 刘冰, 林秦文, 薛纳新 (2017) 中国高等植物受威胁物种名录. 生物多 样性, 25, 696-744.]

The Biodiversity Committee of Chinese Academy of Sciences (2021) Catalogue of Life China: 2021 Annual Checklist. Beijing.

Yu FY, Skidmore AK, Wang TJ, Huang JH, Ma KP, Groen TA (2017) Rhododendron diversity patterns and priority conservation areas in China. Diversity and Distributions, 23, 1143-1156.

Yu FY, Wang TJ, Groen TA, Skidmore AK, Yang XF, Geng YY, Ma KP (2015) Multi-scale comparison of topographic complexity indices in relation to plant species richness. Ecological Complexity, 22, 93-101. 
Yu FY, Wang TJ, Groen TA, Skidmore AK, Yang XF, Ma KP, Wu ZF (2019) Climate and land use changes will degrade the distribution of rhododendrons in China. Science of the Total Environment, 659, 515-528.

Zhang YX, Ren M, Xiao C (2018) The analysis of geographical bias in the collection of Chinese Rhododendraceae plants based on the data of National Specimen Information Infratructure. Frontiers of Data \& Computing, 9(5), 7283. (in Chinese with English abstract) [张玉雪, 任敏, 肖翠 (2018) 基于国家标本资源共享平台数据的中国杜鹃花科 植物标本采集地理偏差分析. 科研信息化技术与应用, 9(5), 72-83.]

Zhuang P (2012) Discuss on the Rhododendron geographical distribution types and their cause of formation in China. Guihaia, 32, 150-156. (in Chinese with English abstract) [庄 平 (2012) 中国杜鹃花属植物地理分布型及其成因的探 讨. 广西植物, 32, 150-156.]

Zhuang P, Wang F, Shao HM (2013) Comparative study on Rhododendron and its distribution in W-Sichuan and SE-Tibet. Guihaia, 33, 79197, 803. (in Chinese with English abstract) [庄平, 王飞, 邵慧敏 (2013) 川西与藏 东南地区杜鹃花属植物及其分布的比较研究. 广西植物, 33, 791-797, 803.]

(责任编委: 张健 责任编辑: 黄祥忠)

•新书推介・

\section{The Wild Flowers of Japan, Revised Edition介绍}
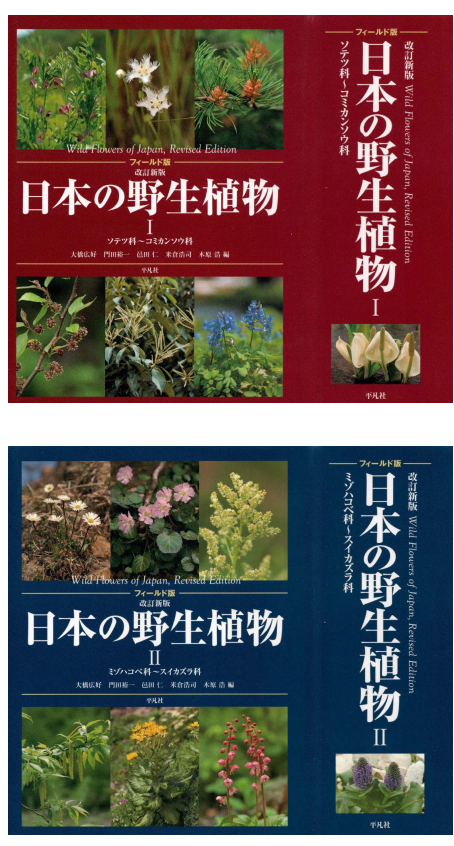

The Wild Flowers of Japan, Revised Edition. Field Version. Ohashi H, Kadota Y, Murata J, Yonekura K and Kihara H (eds), Vols. 1-2, 25 June 2021. Heibonsha Ltd., Publisher, Tokyo. 第一卷: 苏铁科一叶下珠科. 共717页+图版668幅; 第二卷: 沟繁缕科一忍冬科. 共741 页+图版664幅。

1982年日本首发3卷版《日本野生植物・草本》, 深受读者欢迎, 考虑到野外携带的 方便性, 1985年出版了简易版本。基于此, 1989年出版了《日本野生植物・木本》并于1993 年完成其简易版的出版和发行。相隔18年后, 在2015和2017年先后发行5卷版《日本野 生植物·草本》和《日本野生植物・木本》的基础上，大桥广好教授率领团队于2021年6月 25 日出版了简易版《日本野生植物，修订版》(两卷)。该简易版体积小 $(12.8 \mathrm{~cm} \times 17.4 \mathrm{~cm})$, 携带方便, 受到读者的欢迎。

书中涵盖200科1,360属4,800种, 其中191科1,346属为原产日本和常见栽培或归化类 群(如: 银杏属、泡桐属、狭义李属、楝属等), 种类分布日本全国, 即从西部的琉球、南 部的冲绳到北部的北海道等地区。该书由大桥广好教授(东北大学)主编, 门田裕一博士 (国立自然科学博物馆)、邑田 仁教授(东京大学)、米仓浩司博士(冲绳Churashima研究中 心)等学者共同编著, 81位作者合作撰写。书中10,500幅图由专业摄影师木原 浩与其他作 者共同完成。该简易版所含种类及照片与原版保持一致，仅简化了种的描述并压缩了图 片的大小。

该书包含植物种类全面、类群鉴定准确、图版编排精美、易于检索, 尤其在查找不同卷册的科名时相当方便。第一卷的 内一和内二页排列有第二卷所含植物科名及所在页码, 第二卷的内一和内二页排列有第一卷所含植物科名及所在页码。读者 在使用任一卷册时, 能准确了解其他科的位置, 依次找到所含相应种类图片的出处。

购买链接: https://www.heibonsha.co.jp/book/b572943.html。 